\title{
Milliliter per Mole per Minute
}

National Cancer Institute

\section{Source}

National Cancer Institute. Milliliter per Mole per Minute. NCI Thesaurus. Code C85718.

Milliliters per mole per minute. 